http://spilplus.journals.ac.za/

407

DIE TERGAAKLIKHEID VAN TAALWETENGKAP VIR SPRAAKHEELKUNDE

Prof E. Al ant

Departement Kommunikasiepatologie

Universitelt van Pretoria

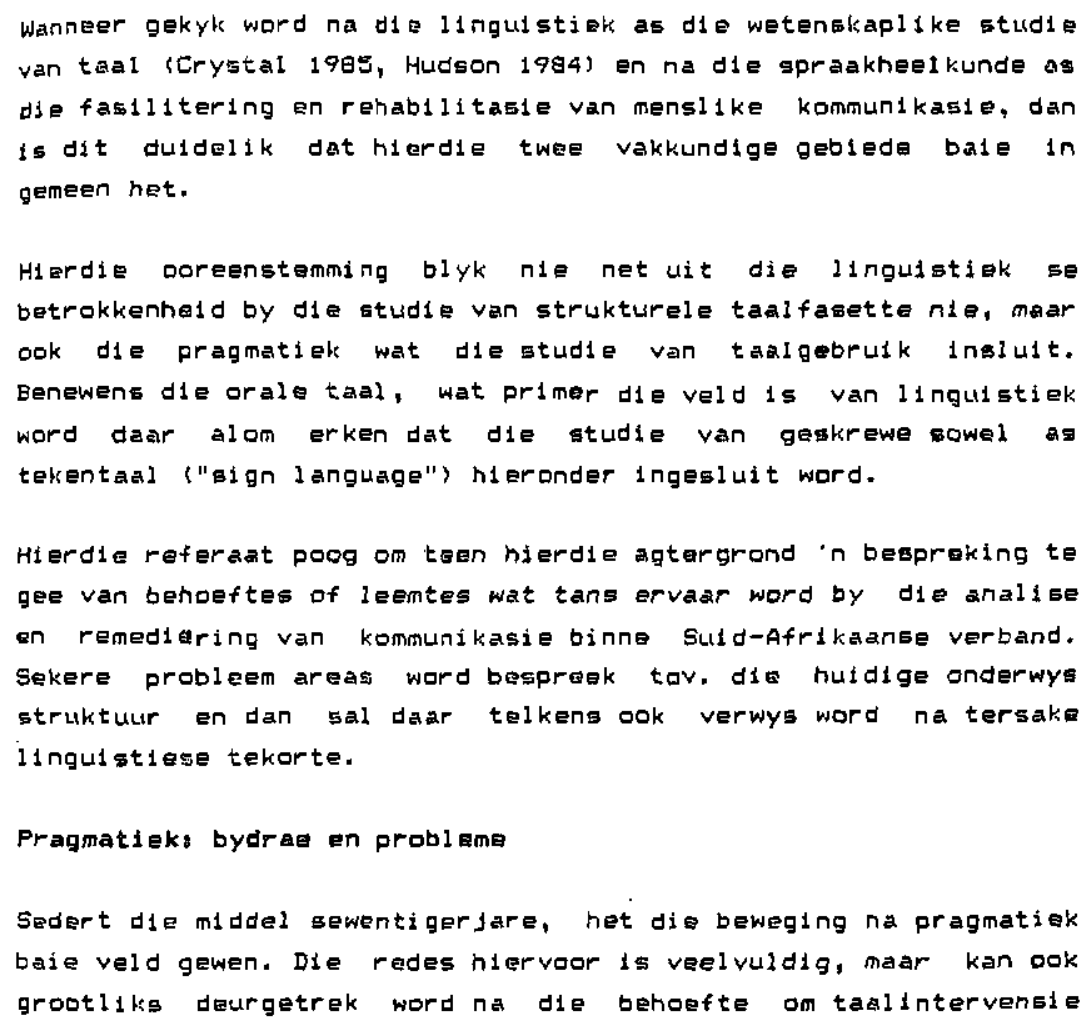


http://spilplus.journals.ac.za/

relevant te maak vir die individu binne sy lewensverband, derhalwe 15 minder tyd aan drilwerk en geisoleerde oefeninge bestee. Hiermee is die klem op die aspekte van "wat " kommunikeer geplaas en nie goveel op "hoe" die kommunikasie gol plaasvind nie. Met hierdie klemverskuiwing en die fokus op intensionele kommunlkasic analiges, ontutaan die vraag egter, maar wat 15 pragmatlek? Dat daar werklik gedrag is wat spesifiek as pragnities beskryf kan word if duidelik. Die vraag anstaan egter of dit as ultsluitlik pragmatiese gedrag gereken kan word. In die verband skryf Gerber (1990, 4) "The clinical $1 \mathrm{mpl}$ icationa for the language elinician are elmple: having identified a "pragmatic" deficit in a language-impaired child, s/he must look high and low for the connecting threads within the langlage domain and outalde the language domain in arder to addregs the problem hol lstically during the intervention process". Hierult is dit duidelik, dat relevante intervensie nie net 18 in kontekstueel-orienteerde tablevaluering nie, maar ook in die daaropvolgende analise van die verbande tussen ander taalareas bv. sintaktiese, semantiese en fonologiese vaardighede en pragmatiese uitvalie. Gaam hiermee le die uitdaging ook am hierdie talprableme ap ' $n$ breer sosidinguistiese vlak te beskou om sodoende seker te maak dat taalintervensie sinvol plaasvind binne 'n bepaalde sosiale konteks. So bv. kan die kind se onvermoe on vrae te inisieer verband hou met sintaktiese probleme om vrae te formuleer, of dit kan gelee wees binne sy sosiale konteks waar kinders nie aangemoedig ward om vrae te stel nie.

D1e talterapeut benodig dus die insette van die toegepaste linguig on te help om sekere assosiasles te bebliryf tugsen diskrete taalvaardighede (bv. Bintaktiese vermoe) en taalgedrag in konteks (bv. gespreksvermoe) on sukses in intervensie beter te kan voorspel. 
http://spilplus.journals.ac.za/

409

Taalvariasies

Die tweede $\mathrm{vlak}$ warop die lingulstiek ' $n$ baie belangrlke bydrae kan lewer in die spraakhealkunde praktyk is die beskrywing en identifisering van relevante talpatrone binne nie-standaardtal (NST) konteks.

Die Interpretasie van talprobleme binne sostaal-relevante kontekse het die afgelope dekade bale aandag geniet in die Amerlkaanse sosio-linguistiese en opvoedkundige literatuur.

Shirley Brice Heath (1984) se identifisering van verskillende interaksionele patrone binne verskillende groepe het daartoe bygedra dat daar met minder riglditeit gekyk lis na die evaluering en 1 nterveneie van kommunikasie. Die bydrae wat gemaak 1 s deur menwe soos Labov (1972), Heath (1994) kan moell1k oorbeklemtoon word wanneer daar gekyk word na ons eie altuaste. Deur hierdie benaderingw vertoon die konsep "normalltelt" 'n bafe groter toleransie vir verskille. Die probleam ontataan egter, dat om werklikwaar betekenlevol te kan evalueer en remediear, begrip van wat "aanvaarbare" kommunikasie binne 'n epesifieke konteks behels ' $n$ voorverelste is. Funksionele taalnavorging binne interaksionele verband is dus in voorverelste vir betekenisvolle intervensie (Alant en Beukes 1998). In Suld-Afrika ig dit in bale ernstige probleem aangesien meeste van die funksionele navorsing gedoen moet word deur spraakterapeute self wat nie noodwendig die sosiolinguistiese agtergrond het om dit suksesvol te kan uitvoer nie. Vrae soos; wat is die nie-standaardtaal gesprekspatrone van voorskoolkinders, en hoe dit verband hol met ouer-kind interakele style, is van primere belang by intervensie binne NsT konteks.

In 'n onlangse studie warna gekyk is na die narratlewe vasidghede van voorskgolse Noord-Sotho eprekende kinders is gevind dat die lnterakslonele patrone van die kinders nie aan verwagtinge voldoen het nie (Alant. Tesner en Taljaardt 1992). 
http://spilplus.journals.ac.za/

Dit wil voorkom asof hierdie kinders meer vertroud 15 met ' $n$ konarratiewe vorim as net die manoloog tipe vertelling. Die implikasie hiervan is, dat die kind nle noodwendig onwilig is om in gesprek te tree rie, maar dat die vorm van storieverteli ing saos vereis binne skoolverband vir hul vreend is. Hierdie bevinding bevestig die mavorsing gedoen deur 0.a. Westby< 1990 ) en Taylor (1989) oor die vaardighede van nie-standaardtal sprekende leorlinge. Dig vour die handiggend dat sourtgelyke inligting van kardinale belang is vir die onderwyser om eadoende sy interaksie met die findars binne die shoolverband te vergemak11k.

Die gebrek aan degglik verantwoorde wetenskaplike studies het tat gevalg dat gevalabalsrywings die fokus geword het van die navorsingsmetodologie van taalintervensie on sodoende eerder die individu mat nomself te vergelyk. Howwel nie ingigeelf negatief rie, 15 die tekort an normatiewe data 'n bale groot struikelulok.

\section{Geskrewe taal}

'n Ander baie belangrike uttvloelgel van dia nie-gtandaardtaal honteks, is dat sodanige kinders probleme ervaar by blootstelling ain geletterdheld, maw aen die standaardtaalvorme nodig vir lese en Ekryf. Hoewel die gebruik van bi-dialektleke metodiek algemean gepropageer word binie die skolastiese konteks (Taylor 19eb), is die praktiese implementering bale moellik, varal siende dat daar nie behoorlike beskrywl ng is van die nie-starlaardtaal vorme nie, veral binne funksionele konteks is nie. Jm dus van onderwysers te verwag om werklikwat begrip te he vir die taalgebruik van die kind en die kind se sosiale en interakstanele konteks is problematies. Hierdie tekort aan voldoende beskrywings van NST vorme in suid-Afrika, bemoeslik die onderwyeer se taak aansienlik, aangesien diar nie sprake kan wes. van $n$ bidialektiese benadering in die onderwys nie. 
http://spilplus.journals.ac.za/

411

\begin{abstract}
Tweedetaal konteks
pleselfde behoefte aan meetinstrumente en sensitfwiteit vir die proses van kammunikasie is nodig om effektief binne tweede taal konteks te kan funksioneer. Dit is alombekend dat een van die grootste ultdagings in die tweedetalal leerkonteke dio gaping tussen studente se eerste en tweede taalvermoe 1s. Die eise wat kognitief aan die kind gestel moet word om ay belangstelling te behou is dus hoer, terwyl sy tweede taal op ' $n$ laer vlak is. Die uttwerk van in wetenskaplik-gefundeerde linguigtiese program 1 E essensieel indien onderwys werklik relevant en sinvol wil wees. Beperkte opleiding van en ondergtelining aan onderwysers in hierdie verband skep egter bale probleme aangasian dio anderwyser gekonfonteer word met in bole komplekse laeraituasia wartoe hulle nie voorberei is nie (5tubbs 1986).
\end{abstract}

\title{
Tekentad
}

Lasatene is daar ongeveer 5 - 6\% van dite algemene populasie wat gehoorgestremd is. 'n Eetekenisvolle persentasis van hierdis menes is ernstig gehoorgestremd en sou dus tekentaal ass kummunikasiemedium gebruik. Dit 1s noodsaaklik dat navorsing gedoen word op tekentaal ook in Suld-Afrika, nis net om ons instaat te gtel an erg gehoorgegtrandes beter te verstean nie, maar ook om die aanleer van hi ardle taal meer effektief te kan bedryf (Lucag 1990). Sintaktiege en morfologiase raels anderliggend aan Suid-Afrikaanae gebaretaal is noodsaaklik vir beter begrip, uitbreiding en toepassing van die taal.

Samevatting: Interdiesiplinere spanwerk; geintegrearde taal intervensio

Aangesien ' $n$ groot persentasip van spraak en taaltarapeute binne skoolvarband werk, word hul in toenemende mate bewusgemakk van die linguistiese prouleme rondom tweedetaal en bi-dialektiear instruksie binne die formele akoolkontaks. Dnderwysers word 
http://spilplus.journals.ac.za/

\begin{abstract}
gekanfronter met rinderg wisse taal spreakwaordelli "onaanvaarbaar" is, sonder enige bewustheld van die andarse interakgianele konteks warlit die kind thag kom.

Die identifikasie van patologie in so'n meertalige konteke is ook baie kompleks. Om ware patelogie te kan identifiseer moet daar deeglik onderskei word tuseen dialektlese verskille en patalogie asook tussen in tweedetaalonvermae en anderligignde taalpatologle. Die sinvolle Mantering van talprobleme by kinderg noodsalk die noug samewerking tusen onderwyser, toegepate 1 inguis en spraak en taalterapeut. Alleen deur noukeurig beplande taalintervensie binne bi-dialektiese en twetalige kantekse kan daar sprake wees van effektiewe onderwys in Suid-Afrika.
\end{abstract}

Om hierdie taalfaktore betekanisvol te kan aanspreek, noodsak besinning oor die taalfilosofie rondam intervensie in die skoulkonteks. 'n Taalfilosofiese benadering wat wel binne so in konteks oorwegg lian ward 1 gi dia voorscelling van Ruiz (1988). Ruiz (19ge) identifiseer drie orientasies tot taal binne skoolkonteks:

1. Die eerste 15, Taal as Probleem. Hier word verskeldenheld gesien as problematies bisna skolastiese verband en word daar eerdar gedink aan ' $n$ "patologiese model" vir die Mantering van vergkillo. Aangesien Mier nie werklik sprake kan wees van patalogie of taalprobleme binne 'n meertalige of bi-dialektiese konteks nie, blyk hierdie orientasie nie primer van toepassing te wees nie.

ii. Die tweede orientasie is die van :Taal as Reg. Hoewel 'n bale belangrike angeleentheid by menteregte, skep hierdie benadering baie moontikhede tot konfrontasie, angesien minderheidstale en die behoud daarvan baie sterk etniese en kulturele implikasies het.

ili. Die derde orientasie is tie van: Taal as Bron (Resourcal. Hier word bedal dat die vergleidenneld talo gesien word as in baje belangrike bron van inligting en kennis oor hoe onderwys en 
http://spilplus.journals.ac.za/

413

\begin{abstract}
metodiek gemodifieer kan word om suksesvol te kan wees vir 'n bapalde groep kinders. Hierdeur word diversiteit duf gesien as in belangrike bron van kennis en ekspertise en sodoende in gelykwaardige status gegee binne die opleidingskanteks.

in voorbeeld van bogenosmde model solu wees dat die onderwyser eensitief is vir verstilile in interaksionele petrane waaraan kinders in haar klas blootgestel is. So gal gy byvoorbeeld begin deur vir verskillende kinders te vra wat is 'nstorie en wie gewoanlik stories vortel binne hulslike konteks sowel as wattar tipe stories (indien enlge) die kind al gehoor het of aan biootgestel 1s. Verskillende tipe stories kan geidentifiseer word wat aan alle deelnemers gelykwaardiga gtatus ge日. Vanult hiordio agtergrand kan die onderwyear nou die tipe storie wat sy wil behandal, toelig en bespraak.

Dif lampte model van taal a bron cou as idasal kon dien vir dia dearstel van in infrastruktuur vir छamewerking tugan sprakkterapeut onderwyser en toegepagte linguis. Om die kinders te ver hierdie kennis en ultgewerkte programme wasby dia toegapaste inguis betrokke is, kan valdoende en betekenisvolle intervensie deur die terapeut en onderwyser, verseker word. Kurrikukum gebasseerde taalonderrig sou dus die sentrale fukuspunt word van intervensie on sodoende die ondersteuning te kan bied aan die onderwyser wat ginvolle anderwys moontlik maak.
\end{abstract}

\title{
Aanbeval $x$ ngs:
}

1. Hoewel mens nie die belang van basiese navorglng wil negeer nie, is daar in sterk behoefta aan toegepaste navoraing in die linguigtiek. Die brug tussen navoraing op tall aignakappe moet gemak word sodat hierdie inllgting verwerk kan word in klinies bruikbare data, ov diagnowilese toetse. 
http://spilplus.journals.ac.za/

414

2. Navorsing mot dia oog op identifieering van vorbande tusseg pragmatiese talprobleme (kantekgtuele evalueringe) en taaldimensies is essengieel om 1ntervensie meer effektief te kan mak.

3. Die beskrywing van taalvarlasies is noodeaaklik veral funksianele werk. wat betref gespreksvaerdighede en taalinhoud binng huis en skoolverband. Hierdie beskrywing sal die onderwyer instaat stel om beter begrip te ontwikliel van die taluvardighaid warmee die kind die skool betree.

4. ' $n$ Groter mate van interdissiplinere samewerking wat gerig is op die orientasia van "taal as bron" (Ruiz 1999). Interabse tussen spraakiterapeut, toegepaste linguis en onderwyser is essensiegl vir beter benutting van onderwys en terapeutiesepersongel. 
http://spilplus.journals.ac.za/

415

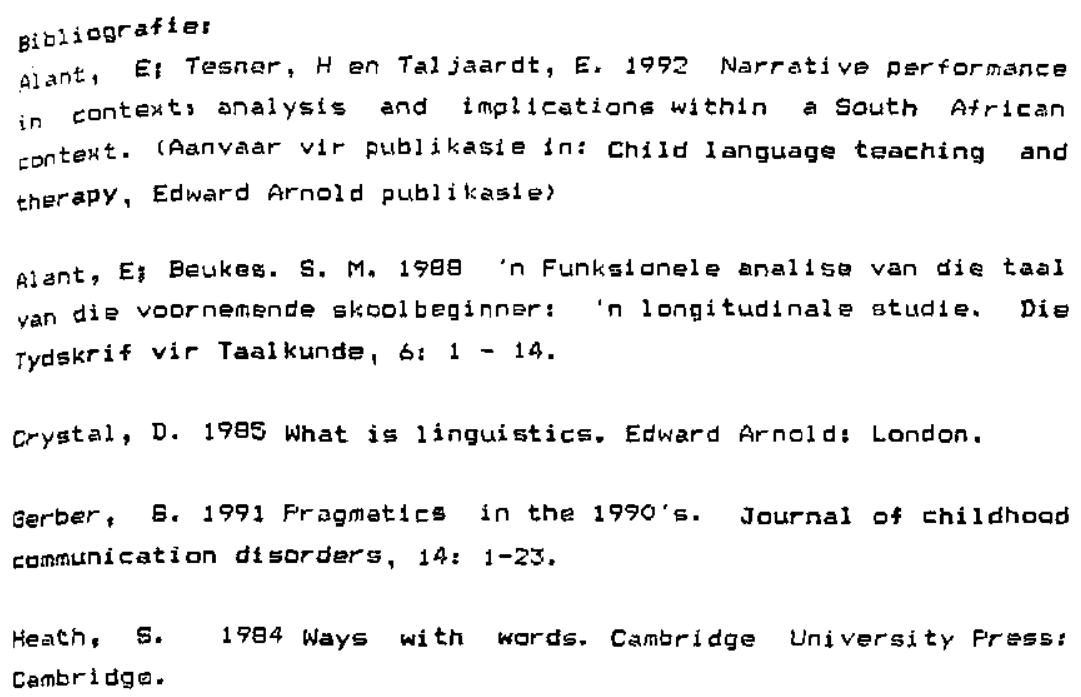

Hudson, R. 1984 Invitation to linguistics. Basil Blackwell: New York.

Labov, W. 1972 The lagic of nonstandard Engl1sh. In $61 \mathrm{~g} 11011, P$. (ed) Language and Social context. Penguins Mlddlesex.

Lucas, C. 1990 sign language resaarch. Gallaudet University Press: Washington.

Westby, C. 1990 Cultural variation in story-telling. In Cole, $L$ and Deal, $v$ sin press\}. Communication alsorders in mutilingual populations. Washington: American speech-language-Hearing Assoriation. 
http://spilplus.journals.ac.za/

Taylor, 0. 1986 Treatment of communication disorders in eulturally and Iinguistically diverse populations. College-Hiil Press: San Digga.

Taylor. D. 1999 Speech and 1 anguage differences and disorders of multicultural populations, In Elackstone, 5 et al (Eds). Handbook of Speech-language Pathology and Audiology. Mosby: St Louis.

Ritz, R. 1998 Orientations in Language F'lanning. In McKay, $s$ and Wong, $C$ (Eds). Language Diversity. Newbury House: London.

Stubbs, M. 1986 Educatianal linguistics. Easil Elackwell: London. 